\title{
BMJ Open Respiratory patient experience of measures to reduce risk of COVID-19: findings from a descriptive cross- sectional UK wide survey
}

Keir EJ Philip (D) , ${ }^{1}$ Andrew Cumella, ${ }^{2}$ Joe Farrington-Douglas, ${ }^{2}$ Michael Laffan, ${ }^{2}$ Nicholas S Hopkinson ${ }^{1,2}$

To cite: Philip KEJ, Cumella A, Farrington-Douglas J, et al. Respiratory patient experience of measures to reduce risk of COVID-19: findings from a descriptive cross-sectional UK wide survey. BMJ Open 2020;10:e040951. doi:10.1136/ bmjopen-2020-040951

- Prepublication history and additional material for this paper are available online. To view these files, please visit the journal online (http://dx.doi. org/10.1136/bmjopen-2020040951).

Received 26 May 2020 Revised 25 August 2020 Accepted 28 August 2020

Check for updates

(c) Author(s) (or their employer(s)) 2020. Re-use permitted under CC BY-NC. No commercial re-use. See rights and permissions. Published by BMJ.

${ }^{1}$ National Heart and Lung Institute, Imperial College London, London, UK

${ }^{2}$ Asthma UK and British Lung Foundation Partnership, London, UK

Correspondence to

Dr Keir EJ Philip;

k.philip@imperial.ac.uk

\section{ABSTRACT}

Objectives To assess the experience of people with long-term respiratory conditions regarding the impact of measures to reduce risk of COVID-19.

Design Analysis of data $(n=9515)$ from the Asthma UK and British Lung Foundation partnership COVID-19 survey collected online between 1 and 8 April 2020.

Setting Community.

Participants 9515 people with self-reported long-term respiratory conditions. $81 \%$ female, age ranges from $\leq 17$ years to 80 years and above, from all nations of the UK. Long-term respiratory conditions reported included asthma (83\%), chronic obstructive pulmonary disease $(10 \%)$, bronchiectasis $(4 \%)$, interstitial lung disease $(2 \%)$ and 'other' $(<1 \%)$ (eg, lung cancer and pulmonary endometriosis).

Outcome measures Study responses related to impacts on key elements of healthcare, as well as practical, psychological and social consequences related to the COVID-19 pandemic and social distancing measures.

Results $45 \%$ reported disruptions to care, including cancellations of appointments, investigations, pulmonary rehabilitation, treatment and monitoring. Other practical impacts such as difficulty accessing healthcare services for other issues and getting basic necessities such as food were also common. $36 \%$ did not use online prescriptions, and $54 \%$ had not accessed online inhaler technique videos. Psychosocial impacts including anxiety, loneliness and concerns about personal health and family were prevalent. $81 \%$ reported engaging in physical activity. Among the $11 \%$ who were smokers, $48 \%$ reported they were planning to quit smoking because of COVID-19. Conclusions COVID-19 and related social distancing measures are having profound impacts on people with chronic respiratory conditions. Urgent adaptation and signposting of services is required to mitigate the negative health consequences of the COVID-19 response for this group.

\section{INTRODUCTION}

COVID-19 is a particular threat for people with long-term respiratory conditions, who are at greater risk of serious disease and death if they become infected. ${ }^{2}$ Recommendations for respiratory patients include

\section{Strengths and limitations of this study}

- This is one of the first studies in the UK to highlight the impact of COVID-19 related measures on people with long-term health conditions.

- The study includes a large sample $(n=9515)$ from a broad range of respiratory conditions, age groups and parts of the UK.

- Key gaps in healthcare provision/access are identified including online prescription and inhaler technique videos, self-management plans and smoking cessation support.

- Although a range of individuals are represented, the sample has a large percentage of people with asthma $(83 \%)$ and is predominantly female $(81 \%)$.

- A lack of data regarding disease severity, and further demographic information of interest such as socioeconomic status, ethnicity and housing, limits the depth of interpretation possible.

being especially careful regarding social distancing measures to reduce SARS-CoV-2 transmission. In the UK, for the most vulnerable, a period of 'social shielding', avoiding face-to-face contact has been advised, ${ }^{34}$ with twin aims of protecting individuals from infection and avoiding a peak of cases in the most vulnerable, which might overwhelm the health and social care system. Measures to reduce the immediate impact of COVID-19 are likely to have some adverse consequences for the population's health and well-being, ${ }^{5-8}$ leading to a so called 'third wave' of COVID-19 related morbidity and mortality in which detrimental health impacts for people with long-term conditions result from interruptions to care provision and health-seeking behaviours. ${ }^{9}$ This is of particular concern given the substantial level of unmet need related to respiratory disease. $^{10-15}$ Identification of health and well-being impacts is required to facilitate 
mitigation interventions, of which examples of successful approaches are being reported. ${ }^{16}$

Data on the experience of people with long-term respiratory conditions regarding the impact of COVID-19 prevention measures is currently lacking ${ }^{17}$ but will be important for understanding of the impacts on these people and to help guide current and future provision to where it is required.

\section{METHODS}

To assess the impact of measures to address COVID-19 on access to key elements of care ${ }^{1819}$ as well as the practical, psychological and emotional consequences of the current situation, we analysed data from an online survey carried out by the Asthma UK (AUK) and British Lung Foundation (BLF) Partnership between 1 and 8 April 2020. The survey was developed by the authors and other colleagues at the Asthma UK and British Lung Foundation (AUKBLF) partnership to improve understanding of the experiences of lockdown and COVID-19 on people with lung conditions in the UK and to find out how AUK-BLF can best support them. The topics were based on areas raised by patients and healthcare professionals as being of particularly vulnerable to disruption and those having potentially important implications for disease management. The core survey was developed by both AUK and the BLF in partnership, with each adding a couple of questions specific to their patient group. In the online supplemental file, the questions that only feature in the AUK or BLF versions are highlighted. The survey results for the core questions were then combined. Any single survey question responses are highlighted as such. The survey was promoted to supporters of both AUK and the BLF and was conducted on Typeform. Initial response targets for the survey were 3000 (AUK) and 1000 (BLF). The survey was distributed to individuals on their mailing lists, placed on the charities' websites and advertised on social media (Facebook, Twitter, Instagram and LinkedIn). Social distancing measures were announced by the UK Government on 23 March. The text of the survey is available in the online supplemental file. Furthermore, during the data collection period, Public Health England recommendations relevant to survey respondents included: (1) all members of the public were advised to stay at home, only being permitted to leave the house for a small number of specific reasons and (2) shielding of 'people with severe respiratory conditions including all cystic fibrosis, severe asthma and severe COPD' who were advised to 'stay at home at all times and avoid any face-toface contact for a period of at least 12 weeks'.

The analysis presented focuses on questions relating to: (1) impacts on healthcare provision, (2) social, psychological and practical responses and (3) sources of support and information. Rating scales are from 0 (lowest) to 10 (highest) unless otherwise specified, for questions relating to how well prepared they felt and levels of anxiety experienced. The three-item UCLA
Loneliness Scale was used to assess loneliness. ${ }^{20}$ The survey questions and response options are provided in the online supplemental file. Data are presented using descriptive statistics. Where a between-group difference was of a potentially clinically significant magnitude, statistical significance was tested using t-test or KruskalWallis tests as appropriate. Respiratory conditions were grouped into 'Asthma' and 'Chronic respiratory disease' (non-asthma) in table 1 so that the composition of the sample was clearer for readers. These data were collected by AUK-BLF as part of routine information gathering and marketing activities, which often relate to topical issues for people with respiratory conditions, in this case COVID-19. All participants consented to their responses being used for research, analysis and publication. Anonymised data were shared with the authors for analysis. The Charity's information governance process supported this, consistent with the General Data Protection Regulation (the primary legislation regarding data protection and privacy in the European Union), and additional external ethical approval was not deemed necessary. Analyses were carried out using Stata V.14. Data used here are not being made publicly available.

\section{Patient and public involvement}

Patients and members of the public were not specifically involved in the design, conduct or reporting of this research. However, the primary focus of this research was to understand the impact of the COVID-19 risk reduction measures on people living with long-term respiratory conditions, and questions were shaped around issues being raised by patients and the public with AUK, BLF, and the clinical staff involved in developing the survey.

\section{RESULTS}

A total of 11124 people started the AUK survey, of which 7748 completed it, while 2518 people started the BLF survey, of which 1856 provided completed responses. Hence, the initial survey data included 9604 full responses. Responses were then removed from people without a lung condition $(n=25)$, people who completed the survey twice within the sampling period $(n=24 \mathrm{BLF}, \mathrm{n}=21 \mathrm{AUK})$ and people who completed both surveys $(n=19)$, which left 9515 individuals' responses for analysis. Data presented here are the combined responses to the core questions that were the same in the BLF and AUK hosted surveys. The BLF hosted version contributed 1787 responses, while the AUK hosted survey contributed 7728 responses. Where the sum of total answers given is less than 9515, this is due to non-response to that specific question. The surveys took respondents an average of (AUK) 8:36 (m/s) and (BLF) 11:35 (m/s) to complete. The exact response rate is not possible to establish given the method by which the survey was publicised including via social media. This final sample was $81 \%$ female, with age ranges from $\leq 17$ years to 80 years and above, and all nations of the UK were represented. Reported lung diseases were $83 \%$ asthma, 
Table 1 Participant characteristics

Chronic respiratory disease (non-asthma) $n=1541$

Asthma $\mathrm{n}=7975(\%(\mathrm{n})) \quad(\%(\mathrm{n}))$

Age group (years)

17 and under

$5.54(439) \quad 0.33(5)$

18-29

12.11 (959)

$30-39$

24.68 (1955)

$0.59(9)$

40-49

$30.60(2424)$

1.90 (29)

$50-59$

18.67 (1479)

$8.93(136)$

$60-69$

$6.26(496)$

$21.47(327)$

70-79

$1.94(154)$

$37.82(576)$

80 and above

$0.19(15)$

$25.21(384)$

Gender (\% female)

82.92 (6562)

$3.74(57)$

Country

$\begin{array}{lcc}\text { England } & 75.35(5981) & 83.33(1275) \\ \text { Scotland } & 13.03(1034) & 9.54(146) \\ \text { Wales } & 7.19(571) & 5.23(80) \\ \text { Northern Ireland } & 4.43(352) & 1.90(29)\end{array}$

Influenza immunisation 2019/2020

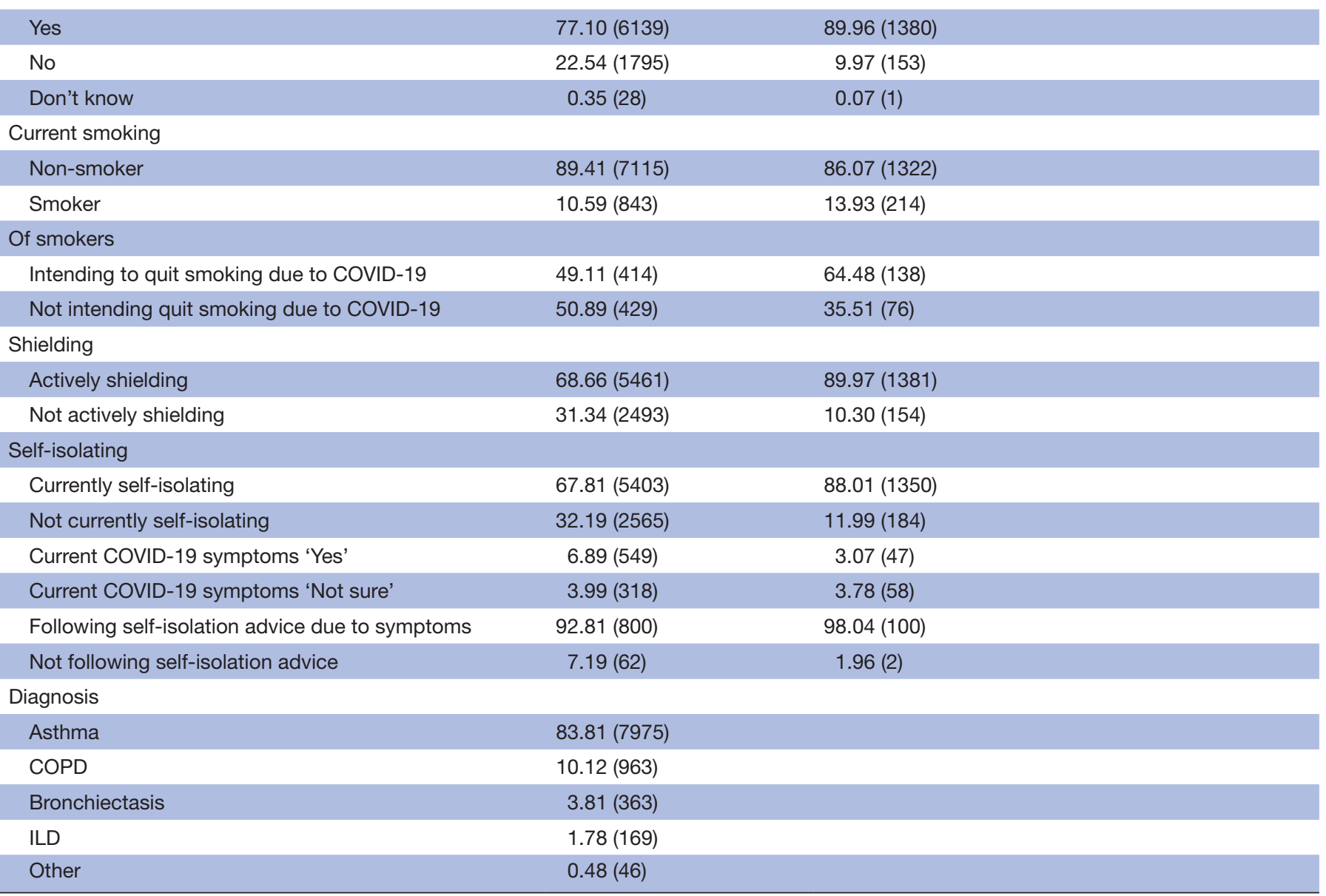

COPD, chronic obstructive pulmonary disease; ILD, interstitial lung disease.

$10 \%$ chronic obstructive pulmonary disease (COPD), $4 \%$ bronchiectasis, 2\% interstitial lung disease (ILD) and $<1 \%$ 'other', for example, lung cancer and pulmonary endometriosis (table 1). Of people who completed the
AUK hosted version of the survey that asked about severity of asthma, $28.25 \%$ (2179) reported having 'difficult' 'severe' or 'brittle' asthma. The BLF hosted version of the survey included an additional question on breathlessness, 
Table 2 Impact of COVID-19 related measures on chronic disease healthcare provision and self-management

\begin{tabular}{|c|c|c|}
\hline Component of disease management & Percentage & Number of observations \\
\hline \multicolumn{3}{|l|}{ Health service provision } \\
\hline GP appointment cancelled & 9.69 & 922 \\
\hline Hospital appointment cancelled & 7.83 & 745 \\
\hline GP phone/remote appointment & 30.93 & 2944 \\
\hline Some form of cancellation or change in service delivery & 44.86 & 4270 \\
\hline \multicolumn{3}{|l|}{ Of those who do Pulmonary Rehabilitation (PR) $(n=553)$} \\
\hline Doing PR at home & 24.77 & 137 \\
\hline PR cancelled & 24.23 & 134 \\
\hline Have enough medications & 93.41 & 8871 \\
\hline Have online prescriptions & 64.38 & 6112 \\
\hline Have a written self-management plan for their condition & 39.56 & 3756 \\
\hline \multicolumn{3}{|l|}{ Have watched online inhaler videos } \\
\hline Yes & 44.11 & 4190 \\
\hline No & 53.57 & 5089 \\
\hline Don't use inhalers & 2.33 & 221 \\
\hline \multicolumn{3}{|l|}{ Physical activity } \\
\hline Able to 'keep active' or do exercise at home & 81.02 & 7682 \\
\hline Not able to 'keep active' or do exercise at home & 18.92 & 1800 \\
\hline \multicolumn{3}{|l|}{ Type of activity } \\
\hline Walks & 47.05 & 4478 \\
\hline Cycling & 6.43 & 612 \\
\hline Run & 7.17 & 682 \\
\hline Yoga & 12.03 & 1145 \\
\hline Gardening & 29.06 & 2817 \\
\hline Housework & 54.16 & 5155 \\
\hline
\end{tabular}

to which $32 \%$ of respondents with non-asthma diagnoses reported being severely breathless (Medical Reserach Council (MRC) dyspnoea score $\geq 4$ ).

\section{Impacts on healthcare provision}

Despite data collection occurring relatively early in the first wave of the UK pandemic, $45 \%$ reported disruptions in healthcare provision, including General Practioner (GP) and hospital appointment cancellations affecting $10 \%$ and $8 \%$ of respondents, respectively, with $31 \%$ reporting having appointments conducted remotely (eg, by phone) (table 2). Respondents reported various additional ways in which healthcare provision had been impacted by COVID-19 (under the free text option 'other'), including cancelled operations, investigations, respiratory nurse appointments and medication reviews, and, finding it difficult to get in contact with relevant care providers for advice and information. Despite being a population by definition with online access, one-third did not access online prescription services and over half had not made use of online inhaler technique videos. Among the $11 \%$ who were smokers, $48 \%$ reported they were planning to quit smoking because of COVID-19. A majority of individuals did not have a written self-management plan despite the strong evidence base for this intervention. ${ }^{191}$

Reassuringly, respondents reported high levels of physical activity, with $81 \%$ being 'able to keep active or do exercise at home' (table 2). Most frequently reported activities include walks (47\%), housework (54\%) and gardening (29\%)(table 2). In addition to the activities listed in table 2, $7 \%$ of respondents reported 'other' activities including home exercise bikes, trampolining, tennis, weights, skipping, home PR, pilates, YouTube exercise videos, zumba/dance and Wii fit.

\section{Social and psychological responses}

High levels of anxiety about COVID-19 were reported, mean (SD) anxiety level 8.03 (2.07), slightly higher in women than men $(8.13(1.99)$ vs 7.55 (2.28) (t-test $\mathrm{p}<0.001)$ ) and decreasing slightly with age (figure 1 , Kruskal-Wallis $\mathrm{p}<0.001$ ). Only $34 \%$ of men and $24 \%$ of women felt that they were 'coping well' (t-test for between group difference $\mathrm{p}<0.001)$. Older age groups were more likely to report coping well with $47 \%$ of $70-79$ year olds, steadily decreasing to $17 \%$ in the 18-29 years old group (Kruskal-Wallis $\mathrm{p}<0.001$ ). Respondent had various 


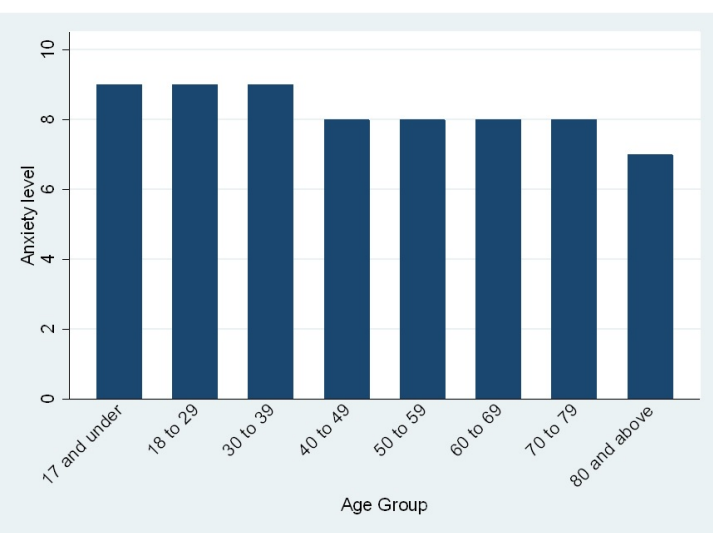

Figure 1 A bar chart of median anxiety level by age group. We conducted the Kruskalr-Wallis $\mathrm{H}$ test to determine if there is a statistically significant difference between anxiety levels in different age groups. This test was selected due to the marked left shift in the data. Sample sizes in each group are reported in table 2 . This test demonstrated statistically significant differences between groups $\left(\chi^{2} 153.895\right.$ with $7 \mathrm{df}$, probability=0.0001).

concerns, most commonly reported being 'concern about lung condition' (64\%) and concern about family (61\%). Interestingly, both showing similar variations related to age and gender as that seen in anxiety and 'coping well', with a higher percentage of females and younger people reporting concerns.

The majority $(87 \%)$ of respondents lived with another person; $51 \%$ felt they lacked companionship 'some of the time' or 'often' and 52\% reported feeling left out of things 'some of the time' or 'often'. Sixty-six per cent of respondents felt 'isolated from others'. Combining the scores for these three statements (modified three-item UCLA Loneliness Score), ${ }^{20} 3$ being the lowest score for loneliness and 9 the highest, the mean loneliness rating was 5.12 (1.80), with broadly similar levels in women and men 5.21 (1.81) versus 4.74 (1.72), although the difference was statistically significant (t-test $\mathrm{p}<0.001)$. Similarly, although in this large sample, the Kruskal-Wallis test showed values were not equal for age groups $(p<0.001)$ and disease types $(p<0.001)$; the differences in loneliness ratings between them were relatively small (online supplemental table E1).

Of note, responses in those who reported that they were actively shielding suggested only slightly higher levels of loneliness to those who were not, at 5.23 and 4.85 (t-test $\mathrm{p}<0.001$ ), respectively (online supplemental table E1). A percentage of 19.54 of respondents had received the government letter or text message advising them to shield, of whom 98\% were doing so. Mean perceived preparedness for COVID-19 was 6.41 (1.7) out of 10 . Again, although there were statistically significant differences related to gender ( $\mathrm{t}$-test $\mathrm{p}<0.001)$, age (KruskalWallis $\mathrm{p}<0.001$ ) and diagnosis (Kruskal-Wallis $\mathrm{p}<0.001)$, these were small in absolute terms and as such unlikely to be of importance (online supplemental table E2).

\section{Sources of support and information}

Respondents reported having accessed various services to address concerns about COVID-19 or its symptoms. These included NHS 111 online (19\%) (an interactive website for the National Health Service that provides information, guidance and self-management support), which was used more commonly by younger adults $(23 \%-25 \%$ of under 40 year olds, compared with 3\%-9\% of over 60 year olds, Kruskal-Wallis $<0.001$, online supplemental table E2), despite the surveys being online, which imply at least some level of digital literacy in all respondents. GPs had been used by $26 \%$ of respondents, again with a trend towards decreasing use in older ( $>60$ years) age groups (online supplemental table E2). The NHS 111 telephone service (a telephone service for non-emergency health advice and guidance) had been used by $8 \%$ of respondents with a similar decrease in use by older age groups. Though differences between conditions are seen, this is likely due to certain conditions being more represented in certain age groups. For example, the same trends regarding age and NHS 111 online use were seen when asthma was considered alone. Only $1 \%$ of respondents reported using $\mathrm{A} \& \mathrm{E}$, with no substantial differences in absolute values related to gender, age or diagnosis. Fiftyfive per cent of respondents reported not having used 'any resources due to coronavirus or concerns about its symptoms'. Reporting not having used resources was more common in older than younger adults (KruskalWallis $<0.001$, online supplemental table E2). As might be expected, higher percentages of respondents in working age groups were concerned about their financial situation due to missed work.

Respondents made use of various sources for information on COVID-19, the most commonly reported being television $(73 \%)$, news websites $(50 \%)$ and (non-BLF/ AUK) social media $(25 \%)$. Less commonly reported sources of information on COVID-19 include BLF/AUK websites $(17 \%)$ and social media $(14 \%)$, radio $(12 \%)$ and friends and family (8\%) (see online supplemental table E2 for further responses about practical preparedness for COVID-19).

Respondents were particularly interested in having more information about how to manage their lung condition in relation to COVID-19 (65\%), decisions they may need to make if they were to get ill with COVID-19 (49\%) and how to look after their mental health (31\%).

\section{Practical difficulties}

Multiple difficulties were experienced by respondents regarding health impacting practical issues. Twenty-two per cent reported difficulties accessing groceries, while $7 \%$ had difficulties accessing prescriptions (online supplemental table E2)

\section{DISCUSSION}

COVID-19 is having significant impacts on individuals with respiratory disease, generating high levels of anxiety 
and concerns about potential impacts on respondents and their families, compounded by social isolation and loneliness. In addition, many aspects of care have been cancelled or deferred, including pulmonary rehabilitation and severe asthma appointments in secondary and tertiary care on a background of provision that was already failing to meet the needs of many people,${ }^{1011}$ with impacts evident despite relatively recent introduction of distancing measures. Respondents were clearly making an effort to engage in physical activity despite the challenging nature of the situation.

Despite the requirement for physical distancing, social isolation and loneliness can still be avoided, or reduced, through targeted support and intervention. There is growing evidence that COVID-19 disproportionally effects more deprived groups. ${ }^{22}$ Isolation strategies are also likely to impact most heavily on the most disadvantaged individuals with the least economic and social capital.

A key practical issue is that nearly half the respondents who smoke tobacco reported that they intended to quit due to COVID-19. It will be important to ensure that there is provision of appropriate accessible smoking cessation support services to maximise their chance of success both to reduce the occurrence of smoking related disease generally ${ }^{23}$ and to reduce individuals' risk from COVID-19 specifically. ${ }^{24}$ In addition, encouraging uptake of online prescriptions and directing patients to online resources including inhaler technique videos to support self-management, as recommended in the NICE COVID-19 COPD Rapid Guideline Update (NG168), ${ }^{25}$ should be prioritised.

The study sample includes representation from a wide age range, a variety of respiratory conditions and all countries of the UK, but some limitations exist. More detail about disease severity would have been useful for interpreting responses, as this impacts government guidance regarding distancing and shielding measures. The study was online so results may not be representative for digitally excluded individuals. In addition, this study did not assess the views on the use of face masks, which has been found to be protective, to some extent, for mental health in China. ${ }^{26}$ This would be of interest to explore further in the UK population. Finally, the cross-sectional nature of this study does not allow for longitudinal change of the level of psychiatric comorbidity, which in patients with respiratory disorders may have a higher baseline prevalence than the general population even prior to the COVID-19 pandemic. $^{27}$

\section{CONCLUSION}

Measures to reduce the risk of COVID-19 are having profound impacts on people with lung disease including widespread disruption to fundamental components of healthcare services, high levels of anxiety and loneliness. There is an urgent need to adapt services to address these needs and improve signposting of individuals to existing resources, in order to mitigate negative health consequences and provide appropriate care to this vulnerable group.

Correction notice This article has been corrected since it was published. The authors name have been updated as Keir EJ Philip and Nicholas S Hopkinson.

Twitter Keir EJ Philip @keirphilip and Andrew Cumella @acumella

Acknowledgements The authors would like to thank Sarah MacFadyen for her work developing the survey and the respondents for completing the survey.

Contributors All authors developed the survey, and KP performed the data analysis and wrote the first draft. All authors contributed to revisions of this first draft and approved the final version.

Funding KP was supported by the Imperial College Clinician Investigator Scholarship, which is managed within Imperial College London, and does not have a specific award/grant number.

Disclaimer The funders had no say in the design and conduct of the study; collection, management, analysis and interpretation of the data; preparation, review or approval of the manuscript; and decision to submit the manuscript for publication.

Competing interests None declared.

Patient and public involvement Patients and/or the public were not involved in the design, or conduct, or reporting, or dissemination plans of this research.

Patient consent for publication Not required.

Provenance and peer review Not commissioned; externally peer reviewed.

Data availability statement No data are available. All data relevant to the study are included in the article or uploaded as supplementary information.

Open access This is an open access article distributed in accordance with the Creative Commons Attribution Non Commercial (CC BY-NC 4.0) license, which permits others to distribute, remix, adapt, build upon this work non-commercially, and license their derivative works on different terms, provided the original work is properly cited, appropriate credit is given, any changes made indicated, and the use is non-commercial. See: http://creativecommons.org/licenses/by-nc/4.0/.

ORCID iD

Keir EJ Philip http://orcid.org/0000-0001-9614-3580

\section{REFERENCES}

1 Docherty AB, Harrison EM, Green CA, et al. Features of 20133 UK patients in hospital with covid-19 using the ISARIC WHO Clinical Characterisation Protocol: prospective observational cohort study. BMJ 2020;369:m1985

2 Williamson EJ, Walker AJ, Bhaskaran K, et al. Factors associated with COVID-19-related death using OpenSAFELY. Nature 2020;584:430-6.

3 Kmietowicz Z. Covid-19: highest risk patients are asked to stay at home for 12 weeks. BMJ 2020;368:m1170.

4 England PH. Guidance on shielding and protecting people defined on medical grounds as extremely vulnerable from COVID-19 2020, 2020. Available: https://www.gov.uk/government/publications/ guidance-on-shielding-and-protecting-extremely-vulnerablepersons-from-covid-19/guidance-on-shielding-and-protectingextremely-vulnerable-persons-from-covid-19 [Accessed 9 Apr 2020].

5 Steptoe A, Shankar A, Demakakos P, et al. Social isolation, loneliness, and all-cause mortality in older men and women. Proc Natl Acad Sci U S A 2013;110:5797-801.

6 Bu F, Philip K, Fancourt D. Social isolation and loneliness as risk factors for hospital admissions for respiratory disease among older adults. Thorax 2020;75:597-9.

7 Wang C, Pan R, Wan X, et al. Immediate psychological responses and associated factors during the initial stage of the 2019 coronavirus disease (COVID-19) epidemic among the general population in China. Int J Environ Res Public Health 2020;17. doi:10.3390/ijerph17051729. [Epub ahead of print: 06 Mar 2020].

8 lob E, Steptoe A, Fancourt D. Abuse, self-harm and suicidal ideation in the UK during the COVID-19 pandemic. Br J Psychiatry 2020:1-4.

9 Douglas M, Katikireddi SV, Taulbut M, et al. Mitigating the wider health effects of covid-19 pandemic response. BMJ 2020;369:m1557.

10 Elbehairy AF, Quint JK, Rogers J, et al. Patterns of breathlessness and associated consulting behaviour: results of an online survey. Thorax 2019;74:814-7. 
11 Philip K, Gaduzo S, Rogers J, et al. Patient experience of COPD care: outcomes from the British lung Foundation patient Passport. BMJ Open Respir Res 2019;6:e000478.

12 Kelly JL, Elkin SL, Fluxman J, et al. Breathlessness and skeletal muscle weakness in patients undergoing lung health screening in primary care. COPD 2013;10:40-54.

13 Nacul L, Soljak M, Samarasundera E, et al. Copd in England: a comparison of expected, model-based prevalence and observed prevalence from general practice data. J Public Health 2011;33:108-16.

14 Steiner MC, Lowe D, Beckford K, et al. Socioeconomic deprivation and the outcome of pulmonary rehabilitation in England and Wales. Thorax 2017;72:530-7.

15 Zoumot Z, Jordan S, Hopkinson NS. Emphysema: time to say farewell to therapeutic nihilism. Thorax 2014:69:973-5.

16 Tan W, Hao F, Mclntyre RS, et al. Is returning to work during the COVID-19 pandemic stressful? A study on immediate mental health status and psychoneuroimmunity prevention measures of Chinese workforce. Brain Behav Immun 2020;87:84-92.

17 Tran BX, Ha GH, Nguyen LH, et al. Studies of novel coronavirus disease 19 (COVID-19) pandemic: a global analysis of literature. Int $J$ Environ Res Public Health 2020;17. doi:10.3390/ijerph17114095. [Epub ahead of print: 08 Jun 2020].

18 Hopkinson NS, Molyneux A, Pink J, et al. Chronic obstructive pulmonary disease: diagnosis and management: summary of updated NICE guidance. BMJ 2019;366:I4486.

19 White J, Paton JY, Niven R, et al. Guidelines for the diagnosis and management of asthma: a look at the key differences between BTS/ SIGN and NICE. Thorax 2018;73:293-7.
20 Hughes ME, Waite LJ, Hawkley LC, et al. A short scale for measuring loneliness in large surveys: results from two population-based studies. Res Aging 2004;26:655-72.

21 Zwerink M, Kerstjens HA, van der Palen J, Palen J, et al. (Cost-) effectiveness of self-treatment of exacerbations in patients with COPD: 2 years follow-up of a RCT. Respirology 2016;21:497-503.

22 Rose TC, Mason K, Pennington A, et al. Inequalities in COVID19 mortality related to ethnicity and socioeconomic deprivation. medRxiv 2020.

23 Royal College of Physicians. Hiding in plain sight: treating tobacco dependency in the NHS, 2018. Available: https://www.rcplondon. ac.uk/projects/outputs/hiding-plain-sight-treating-tobaccodependency-nhs

24 Hopkinson NS, Rossi N, El-Sayed Moustafa J, et al. Current tobacco smoking and risk from COVID-19: results from a population symptom APP in over 2.4 million people. medRxiv 2020.

25 National Institute for Clinical Excellence. COVID-19 rapid guideline: community-based care of patients with chronic obstructive pulmonary disease (COPD), 2020. Available: https://wwwniceorguk/ guidance/ng168

26 Wang C, Pan R, Wan X, et al. A longitudinal study on the mental health of general population during the COVID-19 epidemic in China. Brain Behav Immun 2020;87:40-8.

27 Zhang MWB, Ho RCM, Cheung MWL, et al. Prevalence of depressive symptoms in patients with chronic obstructive pulmonary disease: a systematic review, meta-analysis and meta-regression. Gen Hosp Psychiatry 2011;33:217-23. 